\title{
Blocking Proinflammatory Cytokine Release Modulates Peripheral Blood Mononuclear Cell Response to Porphyromonas gingivalis
}

Ezel Berker, ${ }^{* \dagger}$ Alpdogan Kantarci, ${ }^{\dagger}$ Hatice Hasturk ${ }^{\dagger}$ and Thomas E. Van Dyke ${ }^{\dagger}$

Background: Chronic periodontitis (CP) is an inflammatory disease in which cytokines play a major role in the progression of disease. Anti-inflammatory cytokines (interleukin 4 [IL-4] and IL-10) were reported to be absent or reduced in diseased periodontal tissues, suggesting an imbalance between the proinflammatory and anti-inflammatory mediators. This study tests the hypothesis that there is cellular crosstalk mediated by proinflammatory and anti-inflammatory cytokines and that blocking proinflammatory cytokine (tumor necrosis factor $-\alpha[$ TNF- $\alpha]$ and IL-1) production will enhance antiinflammatory cytokine (IL-4 and IL-10) production from peripheral blood mononuclear cells (PBMCs) in response to Porphyromonas gingivalis.

Methods: PBMCs were isolated from individuals diagnosed with $\mathrm{CP}$ or healthy individuals and cultured for 24 hours. Concanavalin A (ConA) was used as an activator of lymphocyte function. Live and heat-killed $P$. gingivalis or lipopolysaccharide from $P$. gingivalis were used as the bacterial stimulants. TNF- $\alpha$ and IL- 1 production was neutralized by specific antibodies against TNF- $\alpha$ and IL- $1 \alpha$ or IL- $\beta$. Culture supernatants were evaluated by enzyme-linked immunosorbent assay for TNF- $\alpha$, IL-1 $\beta$, IL-4, and IL-10 production.

Results: Live $P$. gingivalis did not result in any significant IL-10 or IL-4 release, whereas heat-killed $P$. gingivalis led to a significant increase in IL-10 levels compared with unstimulated or live $P$. gingivalis-stimulated cells from both healthy individuals or those with CP. Overall, PBMCs from patients with CP produced significantly lower IL-10 in response to ConA and P. gingivalis, suggesting chronic suppression of the anti-inflammatory cytokine production. Blocking the proinflammatory cytokine response did not result in any substantial change in IL-10 or IL-4 response to live $P$. gingivalis. Blocking the proinflammatory cytokine response restored IL-10 production by cells from $C P$ in response to $P$. gingivalis lipopolysaccharide.

Conclusions: These findings suggest that PBMCs from patients with CP have suppressed anti-inflammatory cytokine production that can, in part, be restored by neutralizing proinflammatory cytokines. Monocytes are an important source of IL-10 production, and monocyte-derived IL-10 might play a regulatory role in the pathogenesis of CP. J Periodontol 2013;84:1337-1345.

\section{KEY WORDS}

Interleukin-4; interleukin-10; monocytes; periodontitis; Porphyromonas gingivalis.

\footnotetext{
* Department of Periodontology, Faculty of Dentistry, University of Hacettepe, Ankara, Turkey.

$\dagger$ Department of Periodontology, Forsyth Institute, Cambridge, MA.
} 


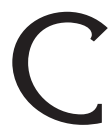
hronic inflammatory periodontal diseases are associated with Porphyromonas gingivalis as a major pathogen with a large array of virulence factors. ${ }^{1-4}$ Complex immune responses to $P$. gingivalis play an important role in the progression of tissue breakdown in chronic periodontitis (CP). ${ }^{4-7}$ Lymphocytes ( $\mathrm{B}$ and $\mathrm{T}$ cells) as well as mononuclear phagocytes are present in diseased tissues and participate in host defense by actively producing cytokines. ${ }^{7,8}$ Cytokine balance is considered to play an important role in the initiation and progression and host modulation of periodontal disease. ${ }^{9,10} \mathrm{~T}$ cells can be categorized into various subgroups with different functions. ${ }^{11} \mathrm{~T}$ helper 1 (Th1) clones produce interleukin-2 (IL-2), interferon- $\gamma$ (IFN- $\gamma$ ), and tumor necrosis factor- $\alpha$ $(\mathrm{TNF}-\alpha)$, whereas Th2 clones produce IL-4, IL-5, IL-6, and IL-13. ${ }^{11}$ IL-10 was originally described as a product of Th2 clones, but it is now known that Th1 cells and activated monocytes/macrophages also secrete IL-10 in humans, suggesting a critical role for IL-10-mediated regulation of the inflammatory response. ${ }^{12}$ Various studies have reported decreased Th1 and increased Th2 responses in CP, with gingival mononuclear cells producing higher levels of IL- 5 and IL- 6 but not IL2. ${ }^{13}$ Memory $\mathrm{T}$ cells from the peripheral blood of patients with $\mathrm{CP}$ stimulated in vitro with $P$. gingivalis were shown to produce significantly more IL-4 than cells from healthy individuals. ${ }^{14}$ However, it is not clear how the interactions between $\mathrm{T}$-cell clones and monocytes/macrophages might modulate disease activity and chronicity and at what stage IL-10 is involved.

Evidence suggests that stimulation of peripheral blood mononuclear cells (PBMCs) from individuals with $C P$ and gingivitis results in upregulation of IFN- $\gamma$ and IL-13, whereas IL-4 and IL-10 are downregulated. ${ }^{15}$ An imbalance of cytokine production may induce bone and collagen breakdown in periodontal disease, as demonstrated by cell infiltration and elevated levels of proinflammatory cytokines (IL-1, TNF, and IL-6) associated with active tissue breakdown in CP and other chronic inflammatory diseases such as rheumatoid arthritis. ${ }^{16-19}$ One theory suggests that a lack of, or insufficient, response in antiinflammatory cytokines is associated with the upregulation of proinflammatory cytokines. ${ }^{20,21}$ Therefore, it is hypothesized in this study that the release of anti-inflammatory cytokines will be restored when proinflammatory cytokines are neutralized after triggering the host response with $P$. gingivalis. The purpose of this study is to analyze $P$. gingivalis-mediated IL-4 and IL-10 production from PBMCs after blocking of TNF- $\alpha$ and IL-1 in the presence and absence of donor periodontitis.

\section{MATERIALS AND METHODS}

\section{Selection of Participants}

Twelve individuals were included in the study. Six of these participants (four males and two females) were diagnosed with moderate-to-severe generalized $C P$ as defined by the accepted criteria, ${ }^{22}$ whereas six healthy donors (three males and three females) were used as matched controls with respect to age, sex, and race. The study was approved by the Institutional Review Board at Boston University Medical Center, and written informed consent was obtained from all individuals before evaluation. The study was conducted from 2004 to 2005. Nine of 12 of the individuals were nonsmokers. Mean age was $39.3 \pm 9.8$ years. None of the individuals had any known systemic disorders or used antibiotics or anti-inflammatory medications within 3 months of the experiment. The following were exclusion criteria: 1) participants with active infectious diseases, such as hepatitis, human immunodeficiency virus, and tuberculosis; 2) participants chronically treated with medications (phenytoin, cyclosporin A, or calcium channel blockers); and 3) females who were lactating or pregnant.

\section{P. gingivalis Culture and Lipopolysaccharide Production}

$P$. gingivalis strain A7436 was cultured as previously described. ${ }^{23,24}$ After 24 hours of anaerobic growth in Schaedler broth, ${ }^{\dagger}$ bacteria were harvested by centrifugation, washed with sterile pyrogen-free saline, and adjusted to an $\mathrm{OD}_{660}$ of 1.0 (approximately $1 \times 10^{9}$ colony forming units $/ \mathrm{mL}$ ). Bacterial cell counts were determined in all bacterial cultures to confirm $P$. gingivalis viability prior to cell culture experiments. A Gram stain kit§ was used for assessing the purity of bacterial cell cultures. Three different $P$. gingivalis preparations were used; live $P$. gingivalis was prepared as described above and used at a multiplicity of infection (MOI) of 100 . Heat-killed P. gingivalis was used after adjusting the bacterial cell counts and incubating the $P$. gingivalis colonies in water bath heated to $60^{\circ} \mathrm{C}$ for 20 minutes. MOI for heat-killed bacterial cultures was also set at 100. Lipopolysaccharide (LPS) from $P$. gingivalis A7436 was isolated by the technique described by Westphal and Jann. ${ }^{25}$ Briefly, after 48 to 72 hours of growth, bacteria were washed, pelleted, and resuspended in distilled water. Phenol was melted and slowly

‡ifco, Detroit, MI

$\S$ Thermo Fisher Scientific, Waltham, MA. 
added to an equal volume of bacterial suspension at $68^{\circ} \mathrm{C}$. The emulsion was then chilled on ice for 5 minutes, and phases were separated by centrifugation at 10,000 revolutions per minute for 30 minutes at $4^{\circ} \mathrm{C}$. The aqueous phase (containing the LPS) was removed and dialyzed against distilled water for 72 hours at $4^{\circ} \mathrm{C}$. Phenol-water LPS extract was then lyophilized, purified on cesium chloride isopycnic gradient, and analyzed by sodium dodecyl sulfate polyacrylamide gel electrophoresis. For cell stimulation, $100 \mathrm{ng} / \mathrm{mL}$ $P$. gingivalis LPS was used.

\section{Cell Isolation and Culture}

Ninety milliliters of peripheral venous blood were obtained from each individual into heparinized (10 $\mathrm{U} / \mathrm{mL}$ ) tubes, and mononuclear cells (PBMCs) were isolated using a discontinuous gradient system as described previously. ${ }^{26,27}$ Briefly, peripheral blood was layered on a mixture of resolving medium ${ }^{\|}$and density gradient cell separation medium, 9 and the tubes were centrifuged at $500 \times \mathrm{g}$ for 30 minutes. The PBMC-rich layer was collected and washed twice with phosphate buffered saline ( $\mathrm{pH} 7.4)$, counted, and suspended in cell culture medium ${ }^{\#}$ with $5 \% \mathrm{AB}$ (blood group) serum. PBMCs $\left(1 \times 10^{6}\right.$ cells $\left./ \mathrm{mL}\right)$ were cultured for 24 hours at $37^{\circ} \mathrm{C}$ in a $5 \% \mathrm{CO}_{2}$ atmosphere. After incubation, the cell supernatants were aspirated and saved at $-80^{\circ} \mathrm{C}$ for cytokine analysis. Viability of cells was assessed by blue dye exclusion** under a light microscope.

In parallel experiments, PBMCs were isolated from the same individuals using a discontinuous gradient system $\left(0.25 \times 10^{6} / \mathrm{mL}\right)$. Contaminating non-monocytic cells were removed, and monocyte populations were purified by magnetic cell sorting (MACS) column in the magnetic field of a separator with a monocyte isolation kit using an indirect magnetic labeling system for the isolation of untouched monocytes from human PBMCs. ${ }^{\dagger \dagger}$ Contaminating non-monocytes, i.e. $\mathrm{T}$ cells, NK cells, B cells, dendritic cells, and basophils, were magnetically labeled using a cocktail of biotin-conjugated antibodies against CD3, CD7, CD16, CD19, CD56, CD123, and glycophorin $\mathrm{A}$ and antibiotin microbeads and depleted by retaining them on a MACS column in the magnetic field of a MACS separator, while the unlabeled monocytes passed through the column. Pure monocyte preparations were washed and cultured for 24,48 , or 72 hours in the same way as PBMCs as outlined above. Cells were stimulated with various agents. In addition to live and heat-killed $P$. gingivalis, concanavalin A (ConA) $)^{\neq}$ $(500 \mu \mathrm{g} / \mathrm{mL})$ was used to stimulate T-lymphocyte- mediated cytokine release in PBMC cultures. Escherichia coli LPS (100 ng/mL; strain O55:B5§§) was used to activate monocytes.

\section{Neutralization of Proinflammatory Cytokines (TNF- $\alpha, I L-1 \alpha$, and IL-1 $\beta$ )}

Activity of TNF- $\alpha$, IL- $1 \alpha$, and IL- $1 \beta$ secreted by monocytes in cultures was blocked by monospecific antibodies.||l| Neutralization bioactivity doses (ND 50 ) of antihuman TNF- $\alpha$, IL- $1 \alpha$, and IL- $1 \beta$ antibodies were 0.02 to $0.04,0.05$ to 0.15 , and 0.001 to $0.003 \mu \mathrm{g} / \mathrm{mL}$, respectively. A doseresponse experiment performed to determine the optimal concentrations for neutralizing cytokines indicated that $0.25 \mu \mathrm{g} / \mathrm{mL}$ (anti-TNF- $\alpha$ ), $0.31 \mu \mathrm{g} /$ $\mathrm{mL}$ (anti-IL-1 $\alpha$ ), and $0.031 \mu \mathrm{g} / \mathrm{mL}$ (anti-IL-1 $\beta$ ) were needed to block the cytokine activity from $1 \times 10^{6}$ cells. The inhibition ranged from $87 \%$ to $94 \%$ for TNF- $\alpha, 62 \%$ to $93 \%$ for IL- $1 \alpha$, and $93 \%$ to $94 \%$ for IL- $1 \beta$ production. TNF- $\alpha$, IL- $1 \alpha$, and IL- $1 \beta$ are not produced in significant amounts from resting, ConA-stimulated or live $P$. gingivalisstimulated cell cultures. Neutralization achieved at 24 hours stayed at the same level throughout 48 and 72 hours of culture; therefore, the PBMC data are presented over 24 hours. No major variation between different periods in terms of inhibition was noted (data not shown); antibodies were used in combination to ensure complete neutralization of TNF- $\alpha$, IL- $1 \alpha$, and IL- $1 \beta$.

\section{Enzyme-Linked Immunosorbent Assay}

The levels of TNF- $\alpha$, IL- $1 \alpha$, IL- $1 \beta$, IL-4, and IL-10 production were measured by commercially available enzyme-linked immunosorbent assay (ELISA). The assays were conducted according to the instructions of the manufacturer. For IL- 4 and IL-10 assays, high-sensitivity kits II $_{\text {were }}$ used to detect low levels, whereas ELISA development systems ${ }^{\# \#}$ were used to monitor TNF- $\alpha$, IL- $1 \alpha$, and IL- $1 \beta$ levels. Briefly, diluted standards and standard cytokine dilutions were added to 96-well microplates coated with mouse antihuman antibodies. Biotinylated antihuman antibodies were used as the detection antibody, and streptavidin-horseradish peroxidase was added as the conjugate. Hydrogen peroxide and tetramethylbenzidine were used as the substrate solution, and the reaction was stopped by adding $2 \mathrm{~N}$ sulfuric acid. All samples and

MonoPoly, Flow Laboratories, McLean, VA.

I Histopaque 1119 and Histopaque 1077, Sigma-Aldrich, St. Louis, MO

\# RPMI1640, American Type Culture Collection, Manassas, VA.

* * Trypan blue, Invitrogen, Carlsbad, CA.

†† Monocyte Isolation Kit II, Miltenyi Biotec, Auburn, CA

竍 Sigma-Aldrich.

$\S \S$ Sigma-Aldrich.

III R\&D Systems, Minneapolis, MN.

II R\&D Systems.

\#\# DuoSet ELISA development system, R\&D Systems. 

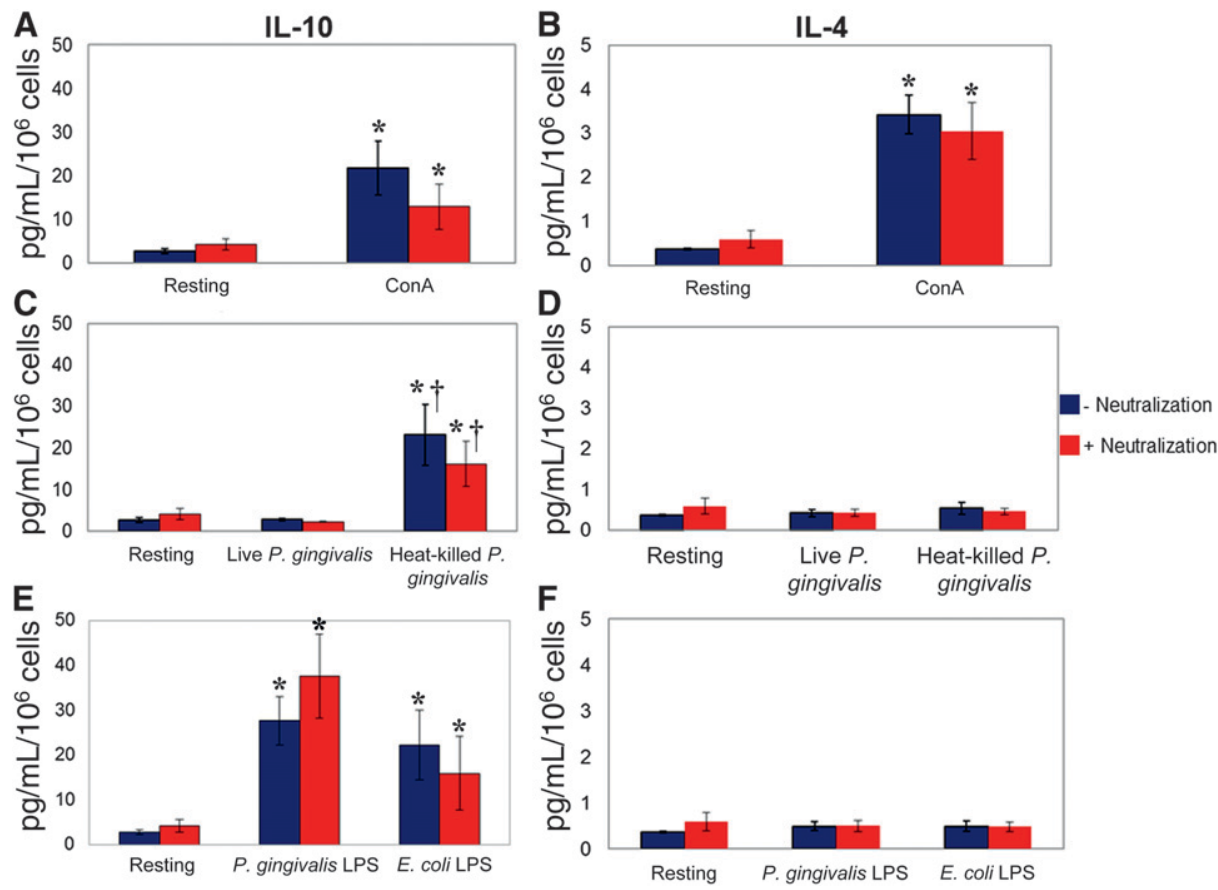

Figure I.

IL-10 and IL-4 release by PBMCS from healthy donors. PBMCs were stimulated in the presence and absence of a combination of neutralizing antibodies to the proinflammatory cytokines TNF- $\alpha(0.25$ $\mu \mathrm{g} / \mathrm{mL}), I L-\mid \alpha(0.3 \mid \mu \mathrm{g} / \mathrm{mL})$, and IL-I $\beta(0.03 \mid \mu \mathrm{g} / \mathrm{mL})$. Each experiment was repeated in duplicate; results represent means \pm SDs. $\boldsymbol{A}$ and $\mathbf{B})$ A specific T-cell activator (ConA; $500 \mu \mathrm{g} / \mathrm{mL}$ ) significantly increased cytokine release compared with unstimulated (resting) cells ( ${ }^{*} \mathrm{P}<0.05$ ). Blocking proinflammatory cytokine release did not significantly change the ConA-induced IL-10 and IL-4 release by healthy cells $(P>0.05)$. C and $\mathbf{D})$ Live P. gingivalis did not significantly induce IL-10 or IL-4 production by the PBMCs $(\mathrm{P}>0.05)$; heat-killed $\mathrm{P}$. gingivalis led to a significant increase in IL-I 0 levels compared with unstimulated cells $\left({ }^{*} \mathrm{P}<0.05\right)$ and live P. gingivalis-stimulated cells $\left({ }^{\dagger} \mathrm{P}<0.05\right)$. Blocking proinflammatory cytokine response did not result in any substantial change in IL-10 or IL-4 response $(P>0.05)$. $E$ and $\mathbf{F})$ P. gingivalis LPS (100 ng/mL) induced a significant increase in IL-10 $(* P<0.05)$, with no impact on IL-4 levels $(P>0.05)$. E. coli LPS (100 ng/mL) induced significant IL-10 production ( $\left.{ }^{\mathrm{P}}<0.05\right)$, with no substantial change in IL-4 levels $(\mathrm{P}>0.05)$. unstimulated (resting) cells $(21.69 \pm 6.20$ versus $2.70 \pm$ $0.53 \mathrm{pg} / \mathrm{mL} / 10^{6}$ cells IL-10 and $3.42 \pm 0.44$ versus $0.37 \pm$ $0.02 \mathrm{pg} / \mathrm{mL} / 10^{6}$ cells IL-4; $P<0.05$; Figs. $1 \mathrm{~A}$ and $1 \mathrm{~B})$. Blocking proinflammatory cytokine release did not significantly change ConA-induced IL-10 and IL-4 release by healthy cells. Live $P$. gingivalis did not result in any significant production of IL-10 or IL-4 $\left(2.80 \pm 0.24 \mathrm{pg} / \mathrm{mL} / 10^{6}\right.$ cells IL-10 and $0.42 \pm 0.09 \mathrm{pg} / \mathrm{mL} /$ $10^{6}$ cells IL-4), whereas heatkilled $P$. gingivalis led to a significant increase in IL-10 levels compared with unstimulated or live $P$. gingivalis-stimulated cells $\left(23.11 \pm 7.27 \mathrm{pg} / \mathrm{mL} / 10^{6}\right.$ cells; $P<0.05$; Figs. $1 \mathrm{C}$ and 1D). Blocking the proinflammatory cytokine response did not result in any substantial change in IL10 or IL-4 response in healthy cells. P. gingivalis LPS induced a significant increase in IL-10 (27.66 $\pm 5.37 \mathrm{pg} / \mathrm{mL} / 10^{6}$ cells) by healthy PBMCs with no effect on IL-4 levels. This response was comparable to LPS from $E$. coli $\left(22.16 \pm 7.77 \mathrm{pg} / \mathrm{mL} / 10^{6}\right.$ cells; Figs. $1 \mathrm{E}$ and $1 \mathrm{~F})$. standards were run in duplicate, and optical density was determined with a microplate reader*** at a 450-nm wavelength. Samples above the standard determination range for optical density readings were assayed again and read at an appropriate dilution to ensure that the levels were within the linear slope of the standard curve.

\section{Statistical Analyses and Data Presentation}

Each experiment was repeated in triplicate, and data are expressed as the mean \pm SD of three separate values for each individual. Data analysis was performed by Mann-Whitney $U$ test, and significance was set at $P<0.05$.

\section{RESULTS}

\section{IL-10 and IL-4 Release by PBMCs From Healthy Donors}

ConA induced reproducibly significant IL-10 and IL-4 production in healthy cells compared with

\section{IL-10 and IL-4 Release by PBMCs From Patients With CP}

PBMCs obtained from patients with $\mathrm{CP}$ failed to produce significant levels of IL-10 in response to ConA compared with those from healthy donors, whereas IL-4 production was also significantly less $\left(4.17 \pm 1.65\right.$ versus $1.81 \pm 0.38 \mathrm{pg} / \mathrm{mL} / 10^{6}$ cells IL-10 and $1.36 \pm 0.39$ versus $0.42 \pm 0.06$ $\mathrm{pg} / \mathrm{mL} / 10^{6}$ cells IL-4; $P<0.05$; Figs. $2 \mathrm{~A}$ and $2 \mathrm{~B}$ ). Likewise, there was a significant loss of IL-10 production in response to heat-killed $P$. gingivalis (12.36 $\pm 4.25 \mathrm{pg} / \mathrm{mL} / 10^{6}$ cells) and LPS from $P$. gingivalis ( $4.25 \pm 1.98 \mathrm{pg} / \mathrm{mL} / 10^{6}$ cells) compared with healthy cells, with no impact on IL-4 production (Figs. 2C and 2D). E. coli LPS generated comparable levels of IL-10 by PBMCs from patients with CP $\left(17.90 \pm 6.30 \mathrm{pg} / \mathrm{mL} / 10^{6}\right.$ cells $)$. Blocking the proinflammatory cytokine response

\footnotetext{
*** Molecular Devices, Sunnyvale, CA.
} 

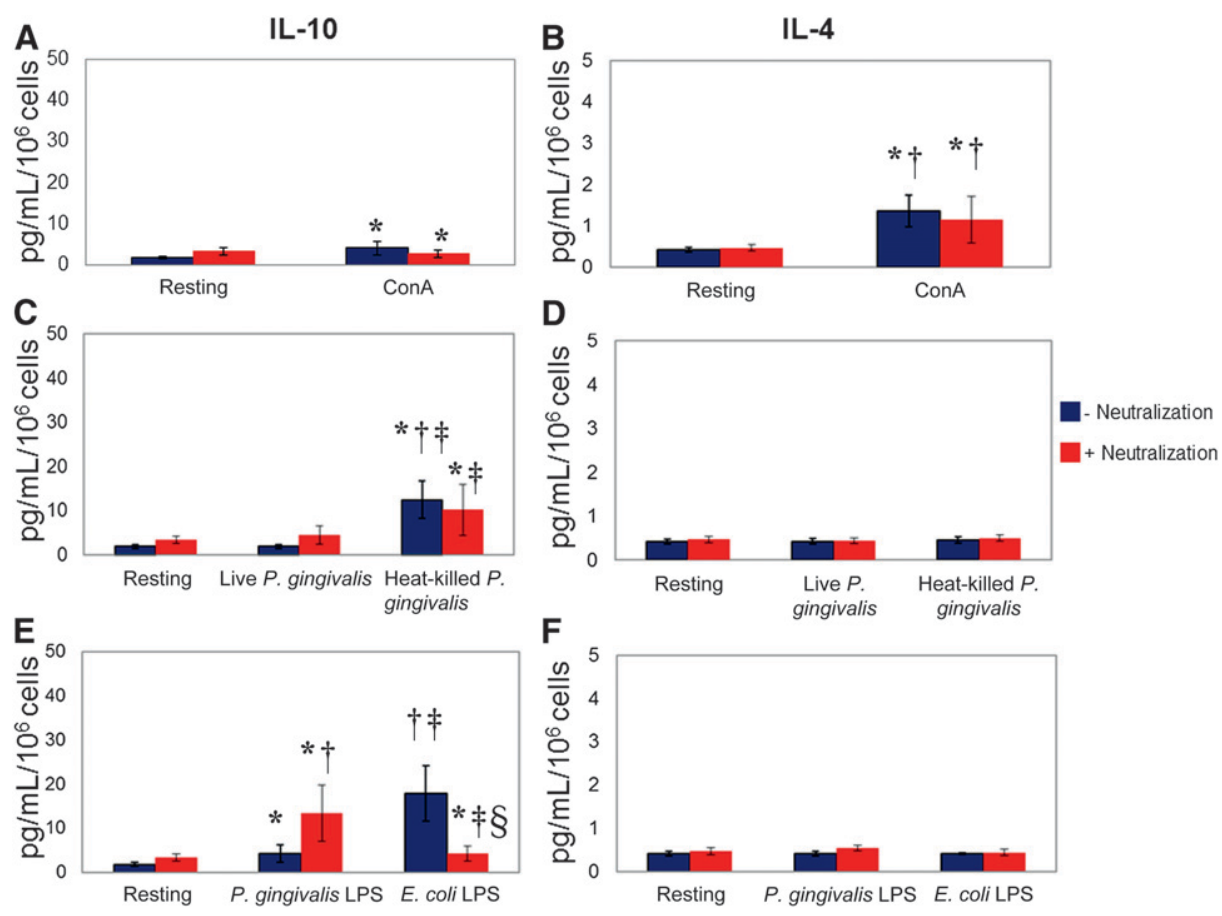

Figure 2.

IL- 10 and IL-4 release by PBMCs from patients with CP. PBMCs were stimulated in the presence and absence of a combination of neutralizing antibodies to the proinflammatory cytokines TNF- $\alpha$ $(0.25 \mu \mathrm{g} / \mathrm{mL}), \quad I L-I \alpha(0.31 \mu \mathrm{g} / \mathrm{mL})$, and $\mid \mathrm{L}-1 \beta(0.031 \mu \mathrm{g} / \mathrm{mL})$. Each experiment was repeated in duplicate; results represent means \pm SDs. $\boldsymbol{A}$ and $\mathbf{B}) \operatorname{ConA}(500 \mu \mathrm{g} / \mathrm{mL})$ stimulation did not produce significant IL-IO in PBMCs from patients with CP compared with unstimulated cells $(P>0.05)$. The difference was significant compared with cells from healthy donors $\left({ }^{*} P<0.05\right)$. IL-4 production was significantly increased compared with unstimulated cells ( $\left.{ }^{\dagger} \mathrm{P}<0.05\right)$ but significantly less than healthy cells ( $\left.{ }^{*} P<0.05\right)$. $\boldsymbol{C}$ and $\left.\boldsymbol{D}\right)$ Live P. gingivalis did not significantly induce IL-10 or IL-4 production ( $\mathrm{P}>0.05$ ); heat-killed $\mathrm{P}$. gingivalis led to a significant increase in IL10 levels compared with unstimulated $\left({ }^{\dagger P}<0.05\right)$ and live $P$. gingivalis-stimulated cells $\left({ }^{\ddagger} \mathrm{P}<0.05\right)$. Blocking the proinflammatory cytokine response did not result in any substantial change in IL-10 or IL-4 response ( $P>0.05)$. IL- 10 production by PBMCs from patients with CP in response to heatkilled $P$. gingivalis was significantly less than the cells from healthy donors ( $\left.{ }^{*} P<0.05\right)$. $\boldsymbol{E}$ and $\left.\boldsymbol{F}\right)$ P. gingivalis LPS (100 ng/mL) did not induce a significant increase in IL-10 or IL-4 levels (P >0.05) compared with unstimulated cells. When IL-I and TNF- $\alpha$ were blocked, P. gingivalis LPS-induced IL10 production was significantly higher than unstimulated cells ( $\left.{ }^{\dagger} \mathrm{P}<0.05\right)$, with no change in IL-4 release. P. gingivalis LPS-induced IL-10 production by the PBMCs from patients with CP was significantly less than the healthy cells with or without neutralization of proinflammatory cytokines $\left({ }^{*} \mathrm{P}<0.05\right)$. E. coli $(100 \mathrm{ng} / \mathrm{mL})$ LPS-stimulated IL-10 by the PBMCs significantly compared with resting $\left({ }^{\dagger} P<0.05\right)$ and $P$. gingivalis LPS-stimulated ( $\left.{ }^{\mp} P<0.05\right)$ cells. When the TNF- $\alpha$ and $I L-I$ responses were blocked, E. coli LPS-induced IL-10 production was significantly reduced $(\mathcal{S P}<0.05)$, significantly lower than the P. gingivalis LPS $\left({ }^{\ddagger} P<0.05\right)$ or healthy cells $\left({ }^{*} P<0.05\right)$.

treated the same way as the PBMCs. Figure 3 demonstrates the time course of IL10 production in response to $P$. gingivalis over 72 hours. As in the case of PBMCs, monocytes failed to produce any detectable IL-10 in response to live $P$. gingivalis, whereas heat-killed $P$. gingivalis led to a statistically significant increase in IL-10 production (Fig. 3A); blocking modestly restored this response (Fig. 3B). Cells were then challenged with LPS from $E$. coli or $P$. gingivalis (Fig. 3C). Both LPS preparations caused significant and parallel IL-10 production from monocytes $(P<0.05)$. Blocking proinflammatory cytokines did not lead to any significant change in IL-10 production in response to $E$. coli LPS, whereas the IL-10 response to LPS from $P$. gingivalis was significantly restored after 48 hours of neutralization (Fig. 3D).

\section{DISCUSSION}

$P$. gingivalis can modulate the innate immune response, rendering the host susceptible to disease by its virulence factors, such as LPS, capsule, and gingipains. ${ }^{1,2,28-31}$ $P$. gingivalis can perturb the cytokine network not only by stimulating the release of cytokines from host cells but also by removing cytokines from the local environment

in part restored the IL-10 production by cells from $\mathrm{CP}$ in response to $P$. gingivalis LPS $(13.38 \pm 6.29$ $\mathrm{pg} / \mathrm{mL} / 10^{6}$ cells) but reduced $E$. coli LPS-induced IL-10 production $\left(4.27 \pm 1.76 \mathrm{pg} / \mathrm{mL} / 10^{6}\right.$ cells $)$ (Figs. 2E and 2F).

\section{IL-10 Production From Monocytes in Response to P. gingivalis}

To identify the contribution of mononuclear phagocytes (monocytes) to overall IL-10 production by the PBMCs, pure monocyte cultures were next obtained by negative selection through MACS and in periodontal lesions. ${ }^{29-34}$ "Proinflammatory" cytokines initiate a profound immune response, whereas IL-4 and IL-10 act as "anti-inflammatory" cytokines and regulate the immune response by controlling the proinflammatory cytokine response. ${ }^{35-39}$ The net outcome of this crosstalk between the proinflammatory and anti-inflammatory arms of the immune response is the downregulation of the excessive and harmful inflammation in infections preventing host-mediated tissue breakdown and controlling the resolution of inflammation. Based on the assumption that CP is attributable to an 

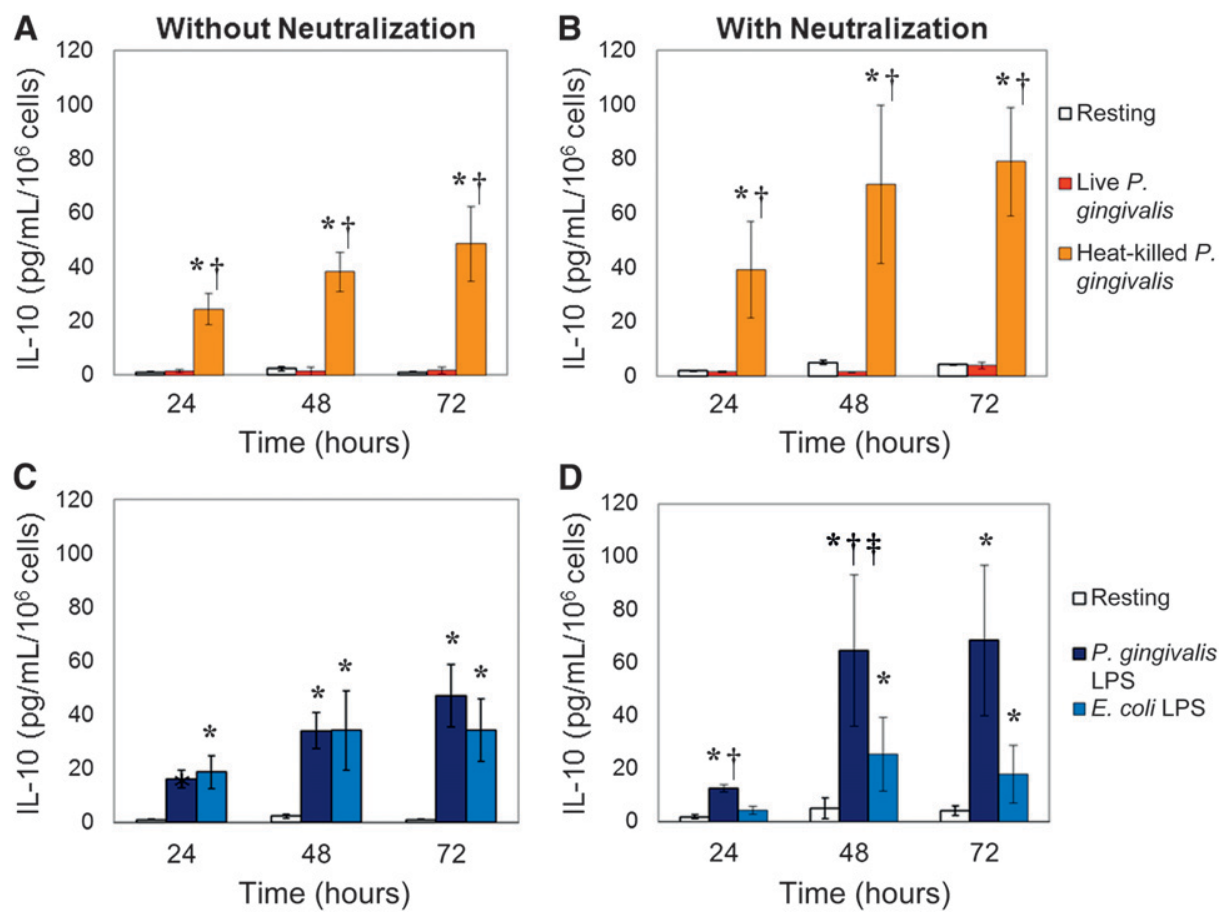

Figure 3.

IL-10 production from monocytes in response to P. gingivalis. Each experiment was repeated in duplicate; results represent means $\pm S D$ s. $\boldsymbol{A}$ and $\boldsymbol{B})$ Live P. gingivalis did not generate any significant IL-IO production by the monocytes; heat-killed P. gingivalis led to a statistically significant increase in $\mathrm{IL}-10$ production compared with resting $(* \mathrm{P}<0.05)$ or live bacteriastimulated ( $\left.{ }^{\dagger} \mathrm{P}<0.05\right)$ cells. Blocking the proinflammatory cytokine activity did not result in any significant change compared with cells that were not exposed to neutralization but were statistically significant compared with resting $\left({ }^{*} \mathrm{P}<0.05\right)$ or live bacteria-stimulated ( $\left.{ }^{\dagger} \mathrm{P}<0.05\right)$ cells with neutralization. C and D) LPS (100 ng/mL) from both E. coli and P. gingivalis caused significant IL-IO production from monocytes compared with resting cells $\left({ }^{*} P<0.05\right)$. Blocking proinflammatory cytokines did not lead to any significant change in IL-10 production in response to $E$. coli LPS $(P>0.05)$, but there was a significant increase in $1 L-10$ response to LPS from P. gingivalis after 48 hours of neutralization ( ${ }^{\ddagger} \mathrm{P}<0.05$ ). At both 24 and 48 hours, P. gingivalis LPS-stimulated IL-10 production by the monocytes was significantly higher than the E. coli LPS-treated cells under neutralization ( $\left.{ }^{\dagger} \mathrm{P}<0.05\right)$.

imbalance between proinflammatory and antiinflammatory cytokines, $, 8,9,15,16,18,19,40$ this study addresses the regulation of anti-inflammatory cytokines in P. gingivalis-stimulated PBMC cultures and the role of proinflammatory cytokines in this process in healthy people and patients with CP. The results demonstrate that heat-killed $P$. gingivalis had a profound impact on IL-10 production in PBMCs with reduced production by the cells from donors with $C P$, suggesting an aberrant IL-10-mediated host response. There was also differential regulation of cytokine release when cells were stimulated with LPS from $P$. gingivalis compared with E. coli, suggesting different Toll-like receptor (TLR) pathways. Blocking proinflammatory cytokine discharge restored $P$. gingivalis LPS-elicited IL-10 production, suggesting that the host response is, at least in part, directed to resolution in the absence of proinflammatory stimuli. The lack of response to live $P$. gingivalis is likely attributable to in vitro degradation of mediators by proteases as reported in similar systems. Overall, these findings indicate that the resolution pathways mediated by IL-10 are downregulated in chronic periodontal inflammation and can only be partially restored when acute proinflammatory cytokine release has been blocked.

$P$. gingivalis synthesizes and secretes high levels of proteolytic enzymes to degrade peptides to essential amino acids as a food source. These bacterial proteases (gingipains) have been shown to cleave and inactivate released cytokines and, as a consequence, are thought to impair the inflammatory response. ${ }^{34,41}$ Gingipains cleave monocyte CD14, result in attenuation of the cellular recognition of bacteria, and sustain chronic inflammation. ${ }^{32}$ In this study, both live $P$. gingivalis and heatkilled $P$. gingivalis are tested. Live cultures did not result in significant IL-10 and IL-4 from PBMCs, whereas heat-killed bacterial preparations led to a substantial anti-inflammatory response, indicating that $P$. gingivalis surface molecules affect the immune mechanisms of the host when the bacterium is not viable. The inhibition of the production of IL- 4 and IL-10 by PBMCs from healthy individuals and patients with $\mathrm{CP}$ elicited by live $P$. gingivalis is interpreted as an in vitro artifact of high gingipain concentration in the absence of serum protease inhibitors. Within the limits of this study, it is not clear whether the inhibition is attributable to an active impact on the transcription or the secretion of IL-4 and IL-10 or post-release proteolytic degradation. The most likely mechanism is proteolytic degradation, which is supported by the previous findings for IL-4 release that demonstrate that gingipain complexes inactivated the Th2 cytokines IL- 4 and IL-5. ${ }^{42}$ It is possible that the same action is being observed for IL-10 release, accounting for broader immunosuppression. 
LPS is among the possible virulence factors, which can still be highly active after the bacteria lose their viability. Therefore, LPS preparation from $P$. gingivalis was tested next. LPS from neither $P$. gingivalis nor $E$. coli stimulated the IL-4 response, suggesting the specificity of the LPS activation of monocytic cells. Conversely, IL-10 was produced by both monocytes and PBMCs in response to $P$. gingivalis LPS and E. coli LPS, supporting the notion that monocytes are an important source of IL-10. Blocking the proinflammatory cytokine response restored IL-10 production by cells from $C P$ in response to $P$. gingivalis LPS but reduced $E$. coli LPS-induced IL-10 production, suggesting that different TLR-mediated responses are involved in LPS-mediated IL-10 production.

Monocytes are assumed to be initially in a quiescent state, and they are stimulated to produce IL-1 by an external stimulus, such as the LPS. This in turn invokes an autocrine IL-1 response and induces the production of the anti-inflammatory cytokine IL-10, which acts to downregulate IL-1 production. To identify the role of mononuclear phagocytes (monocytes) in overall IL-10 production, pure monocyte cultures were obtained by negative selection through MACS, and cells were treated in the same way as the PBMCs at 24, 48, and 72 hours. As in the case of PBMCs, pure monocytes failed to produce any detectable IL-10 in response to live $P$. gingivalis, whereas heatkilled $P$. gingivalis led to statistically significant increases in IL-10 production. Both LPS preparations caused significant and parallel IL-10 production from monocytes $(P<0.05)$. Blocking the proinflammatory cytokines did not lead to any significant change in IL-10 production in response to $E$. coli LPS, whereas IL-10 responses to LPS from $P$. gingivalis were significantly restored after 48 hours of neutralization. These findings suggest that blocking IL-1 and TNF- $\alpha$ may only provide a limited benefit for treatment of IL-10 deficiency in inflammatory periodontal lesions.

Crosstalk between proinflammatory and antiinflammatory cytokines during different stages of inflammation may determine the shift to chronicity. To prevent an uncontrolled inflammatory response and rampant tissue breakdown, the activity of IL-1 and TNF- $\alpha$ must be regulated. This is done naturally by the elaboration of the antiinflammatory cytokines or cytokine antagonists. When the soluble receptors to IL-1 or TNF- $\alpha$ are applied in vivo, pathologic processes can be inhibited in arthritis, septic shock, autoimmune diseases, and periodontitis. ${ }^{43,44}$ Based on these observations, it is hypothesized that neutralization of proinflammatory cytokine release in cell cultures will restore anti-inflammatory cytokine production. More studies are needed to confirm these findings in larger cohorts. Individual variation and various other factors (e.g., smoking) known to play a role in the pathogenesis of periodontal disease can certainly impact the cell response. However, the statistically significant differences obtained in this study suggest that the imbalance between proinflammatory and anti-inflammatory regulatory molecules is impaired in $C P$, and $P$. gingivalis, as well as a crosstalk between cytokines, plays a major role in the process. IL-10 production is suppressed in monocytes from patients with $\mathrm{CP}$, which raises the question of temporality on how the IL-10 release is associated with the colonization of $P$. gingivalis. This is a challenging question, and the answers to whether the changes in the immune response allow colonization or are the result of bacterial invasion has not been clear in vivo. It is possible that both can be true in which an initial decrease/insufficiency of IL-10 could predispose the $P$. gingivalis colonization, whereas $C P$ may be associated with an extended IL-10 function. In primary cell cultures from both healthy and diseased tissues, the phenotypic characteristics of the cells do not change over the study period (24 to 72 hours). However, this report does not directly address whether depressed levels of IL-10 predispose to $C P$ in humans in which $P$. gingivalis is a dominant pathogen or whether $P$. gingivalis directly suppresses the protective and antiinflammatory arm of the immune response. The reported observations may imply that IL-10 has pleiotropic actions at different stages of infection and inflammation depending on the cellular source.

\section{CONCLUSIONS}

The present study suggests that, in $\mathrm{CP}$, antiinflammatory cytokine production is suppressed. The response can, in part, be restored by neutralizing proinflammatory cytokines. The data are also consistent with the suggestion that $P$. gingivalis can contribute to progression of $\mathrm{CP}$ by inducing high levels of inflammatory cytokines and by inhibition of regulator cytokines IL-10 and IL-4.

\section{ACKNOWLEDGMENTS}

This work was supported in part by National Institutes of Health Grants DE15566 and DE19938 (to TVD, HH, and AK) and The Scientific and Technical Research Council of Turkey (to EB). The authors report no conflicts of interest related to this study.

\section{REFERENCES}

1. Grenier D, La VD. Proteases of Porphyromonas gingivalis as important virulence factors in periodontal 
disease and potential targets for plant-derived compounds: A review article. Curr Drug Targets 2011;12: 322-331.

2. Lin L, Li C, Liu J, et al. Virulence genes of Porphyromonas gingivalis W83 in chronic periodontitis. Acta Odontol Scand 2009;67:258-264.

3. Pollreisz A, Huang Y, Roth GA, et al. Enhanced monocyte migration and pro-inflammatory cytokine production by Porphyromonas gingivalis infection. $J$ Periodontal Res 2010;45:239-245.

4. Wang PL, Ohura K. Porphyromonas gingivalis lipopolysaccharide signaling in gingival fibroblastsCD14 and Toll-like receptors. Crit Rev Oral Biol Med 2002;13:132-142.

5. Kornman KS, Page RC, Tonetti MS. The host response to the microbial challenge in periodontitis: Assembling the players. Periodontol 2000 1997;14: 33-53.

6. Bostanci N, Allaker RP, Belibasakis GN, et al. Porphyromonas gingivalis antagonises Campylobacter rectus induced cytokine production by human monocytes. Cytokine 2007;39:147-156.

7. Teng YT. Protective and destructive immunity in the periodontium: Part 1 - Innate and humoral immunity and the periodontium. J Dent Res 2006;85:198208.

8. Gemmell E, Carter CL, Grieco DA, Sugerman PB, Seymour GJ. P. gingivalis-specific T-cell lines produce Th1 and Th2 cytokines. J Dent Res 2002;81: 303-307.

9. Pradeep AR, Roopa Y, Swati PP. Interleukin-4, a T-helper 2 cell cytokine, is associated with the remission of periodontal disease. J Periodontal Res 2008;43:712-716.

10. Zaric S, Shelburne C, Darveau R, et al. Impaired immune tolerance to Porphyromonas gingivalis lipopolysaccharide promotes neutrophil migration and decreased apoptosis. Infect Immun 2010;78: 4151-4156.

11. Mossman TR, Cherwinski H, Bond MV, Giedlen MA, Coffman RL. Two types of helper $\mathrm{T}$ cells clones. $J$ Immunol 1986;136:2348-2356.

12. Opal SM, DePalo VA. Anti-inflammatory cytokines. Chest 2000;117:1162-1172.

13. Fujihashi K, Beagley KW, Kono Y, et al. Gingival mononuclear cells from chronic inflammatory periodontal tissues produce interleukin (IL)-5 and IL-6 but not IL-2 and IL-4. Am J Pathol 1993;142:12391250 .

14. Aoyagi T, Sugawara-Aoyagi M, Yamazaki K, Hara K. Interleukin 4 (IL-4) and IL-6-producing memory Tcells in peripheral blood and gingival tissue in periodontitis patients with high serum antibody titers to Porphyromonas gingivalis. Oral Microbiol Immunol 1995; 10:304-310.

15. Nakajima T, Yamazaki K, Cullinan MP, Gemmell E, Seymour GJ. T-cell antigen specificity in humans following stimulation with Porphyromonas gingivalis. Arch Oral Biol 1999;44:1045-1053.

16. Bozkurt FY, Berker E, Akkuş S, Bulut S. Relationship between interleukin-6 levels in gingival crevicular fluid and periodontal status in patients with rheumatoid arthritis and adult periodontitis. J Periodontol 2000;71:1756-1760.

17. Walmsley M, Katsikis PD, Abney E, et al. Interleukin-10 inhibition of the progression of established collageninduced arthritis. Arthritis Rheum 1996;39:495-503.
18. Han JY, Reynolds MA. Effect of anti-rheumatic agents on periodontal parameters and biomarkers of inflammation: A systematic review and metaanalysis. J Periodontal Implant Sci 2012;42:3-12.

19. Bartold PM, Marshall RI, Haynes DR. Periodontitis and rheumatoid arthritis: A review. $J$ Periodontol 2005;76(Suppl. 11):2066-2074.

20. Katsikis PD, Chu CQ, Brennan FM, Maini RN, Feldmann $M$. Immunoregulatory role of interleukin 10 in rheumatoid arthritis. J Exp Med 1994;179: 1517-1527.

21. van Roon JA, van Roy JL, Gmelig-Meyling FH, Lafeber FP, Bijlsma JW. Prevention and reversal of cartilage degradation in rheumatoid arthritis by interleukin-10 and interleukin-4. Arthritis Rheum 1996;39:829-835.

22. Armitage GC. Development of a classification system for periodontal diseases and conditions. Ann Periodontol 1999;4:1-6.

23. Genco CA, Cutler CW, Kapczynski D, Maloney K, Arnold RR. A novel mouse model to study the virulence of and host response to Porphyromonas (Bacteroides) gingivalis. Infect Immun 1991;59: 1255-1263.

24. Genco CA, Schifferle RE, Njoroge T, Forng RY, Cutler CW. Resistance of a Tn4351-generated polysaccharide mutant of Porphyromonas gingivalis to polymorphonuclear leukocyte killing. Infect Immun 1995;63:393-401.

25. Westphal O, Jann K. Bacterial lipopolysaccharide. Extraction with phenol-water and further applications of the procedure. Methods Carbohydr Chem 1965;5:83-91.

26. Kalmar JR, Arnold RR, Warbington ML, Gardner MK. Superior leukocyte separation with a discontinuous one-step Ficoll-Hypaque gradient for the isolation of human neutrophils. J Immunol Methods 1988; 110:275-281.

27. Böyum A. Isolation of mononuclear cells and granulocytes from human blood. Isolation of monuclear cells by one centrifugation, and of granulocytes by combining centrifugation and sedimentation at $1 \mathrm{~g}$. Scand J Clin Lab Invest Suppl 1968;97:77-89.

28. Zadeh HH, Nichols FC, Miyasaki KT. The role of the cell-mediated immune response to Actinobacillus actinomycetemcomitans and Porphyromonas gingivalis in periodontitis. Periodontol 2000 1999;20:239. 288.

29. Jotwani R, Cutler CW. Fimbriated Porphyromonas gingivalis is more efficient than fimbria-deficient $P$. gingivalis in entering human dendritic cells in vitro and induces an inflammatory Th1 effector response. Infect Immun 2004;72:1725-1732.

30. Suwatanapongched P, Surarit R, Srisatjaluk R, Offenbacher S. Translocation of Porphyromonas gingivalis infected monocytes and associated cellular responses. Asian Pac $J$ Allergy Immunol 2010;28:192-199.

31. Yun PL, Decarlo AA, Collyer C, Hunter N. Hydrolysis of interleukin-12 by Porphyromonas gingivalis major cysteine proteinases may affect local gamma interferon accumulation and the Th1 or Th2 T-cell phenotype in periodontitis. Infect Immun 2001;69: 5650-5660.

32. Sugawara S, Nemoto E, Tada H, Miyake K, Imamura T, Takada H. Proteolysis of human monocyte CD14 by cysteine proteinases (gingipains) from Porphyromonas 
gingivalis leading to lipopolysaccharide hyporesponsiveness. J Immunol 2000;165:411-418.

33. Shimauchi H, Ogawa T, Okuda K, Kusumoto Y, Okada H. Autoregulatory effect of interleukin-10 on proinflammatory cytokine production by Porphyromonas gingivalis lipopolysaccharide-tolerant human monocytes. Infect Immun 1999;67:2153-2159.

34. Hamedi M, Belibasakis GN, Cruchley AT, Rangarajan M, Curtis MA, Bostanci N. Porphyromonas gingivalis culture supernatants differentially regulate interleukin1 beta and interleukin-18 in human monocytic cells. Cytokine 2009;45:99-104.

35. Kinane DF, Lappin DF. Clinical, pathological and immunological aspects of periodontal disease. Acta Odontol Scand 2001;59:154-160.

36. Page RC. The pathobiology of periodontal diseases may affect systemic diseases: Inversion of a paradigm. Ann Periodontol 1998;3:108-120.

37. Paul WE. Interleukin-4: A prototypic immunoregulatory lymphokine. Blood 1991;77:1859-1870.

38. Howard M, O'Garra A. Biological properties of interleukin 10. Immunol Today 1992;13:198-200.

39. Champaiboon C, Yongvanitchit K, Pichyangkul S, Mahanonda R. The immune modulation of B-cell responses by Porphyromonas ginginvalis and interleukin-10. J Periodontol 2000;71:468-475.

40. Yamamato M, Fujihashi K, Hiroi T, et al. Molecular and cellular mechanisms for periodontal disease: Role of
Th1 and Th2 type cytokines in induction of mucosal inflammation. J Periodontal Res 1997;32:115-119.

41. Rudney JD, Chen R, Sedgewick GJ. Intracellular Actinobacillus actinomycetemcomitans and Porphyromonas gingivalis in buccal epithelial cells collected from human subjects. Infect Immun 2001;69:27002707.

42. Tam V, O'Brien-Simpson NM, Chen YY, Sanderson CJ, Kinnear B, Reynolds EC. The RgpA-Kgp proteinaseadhesin complexes of Porphyromonas gingivalis inactivate the Th2 cytokines interleukin-4 and interleukin-5. Infect Immun 2009;77:1451-1458.

43. Marcelletti JF. IL-10 inhibits lipopolysaccharideinduced murine B cell proliferation and cross-linking of surface antigen receptors or ligation of CD40 restores the response. J Immunol 1996;157:3323-3333.

44. Miossec P, Naviliat M, D’Angeac AD, Sany J, Banchereau J. Low levels of IL-4 and high levels of transforming growth factor $\beta$ in rheumatoid synovitis. Arth Rheum 1990;33: 1180-1187.

Correspondence: Dr. Thomas E. Van Dyke, Forsyth Institute, Department of Periodontology, 245 First St. Cambridge, MA 02142. Fax: 617/892-4711; e-mail: tvandyke@forsyth.org.

Submitted July 6, 2012; accepted for publication October 9, 2012. 